\title{
DNA methylation-regulated miR-155-5p depresses sensitivity of esophageal carcinoma cells to radiation and multiple chemotherapeutic drugs via suppression of MAP3K10
}

\author{
WENGUANG LUO ${ }^{1,2^{*}}$, HUANHUAN ZHANG ${ }^{3 *}$, XUE LIANG $^{4,5}$, RAN XIA $^{3}$, \\ HUI DENG ${ }^{3}$, QIYI YI ${ }^{6}$, LEI LV $^{3}$ and LITING QIAN ${ }^{5}$
}

\begin{abstract}
${ }^{1}$ School of Medicine, Shandong University, Jinan, Shandong 250100; ${ }^{2}$ Department of Radiation Oncology,
The First Affiliated Hospital of USTC, Division of Life Sciences and Medicine, University of Science and

Technology of China, Hefei, Anhui 230001; ${ }^{3}$ Department of Cancer Epigenetics Program, Anhui Provincial Cancer Hospital, West Branch of The First Affiliated Hospital of USTC, Division of Life Sciences and Medicine, University of Science and Technology of China, Hefei, Anhui 230031; ${ }^{4}$ Xinxiang Medical University, Xinxiang, Henan 453003;

${ }^{5}$ Department of Radiation Oncology, Anhui Provincial Cancer Hospital, West Branch of The First Affiliated Hospital of USTC, Division of Life Sciences and Medicine, University of Science and Technology of China; ${ }^{6}$ Department of Nuclear Medicine, School of Basic Medical Sciences, Anhui Medical University, Hefei, Anhui 230031, P.R. China
\end{abstract}

Received August 8, 2019; Accepted January 24, 2020

DOI: 10.3892/or.2020.7535

\begin{abstract}
Radiotherapy and chemotherapy are two major treatment options for esophageal carcinoma, and heterogeneous treatment effects are observed in the clinical setting to provide an overall 5-year survival rate of $\sim 20 \%$. Hence, defining the molecular mechanisms that affect the chemoradiotherapy response is vital to achieve an optimal outcome. The present study revealed that miR-155-5p may be involved in esophageal squamous cell carcinoma (ESCC). By means of reverse transcription-PCR, the present study defined its differential expression pattern in six ESCC cell lines that were associated with resistance to radiation. Ectopic expression of miR-155-5p promoted DNA damage repair and induced resistance against radiation by non-homologous end joining repair. It also enhanced chemoresistance, proliferation, and
\end{abstract}

Correspondence to: Dr Lei Lv, Department of Cancer Epigenetics Program, Anhui Provincial Cancer Hospital, West Branch of The First Affiliated Hospital of USTC, Division of Life Sciences and Medicine, University of Science and Technology of China, 107 Huanhu Eastern Road, Hefei, Anhui 230031, P.R. China

E-mail:kelly_lvlei@163.com

Dr Liting Qian, Department of Radiation Oncology, Anhui Provincial Cancer Hospital, West Branch of The First Affiliated Hospital of USTC, Division of Life Sciences and Medicine, University of Science and Technology of China, 107 Huanhu Eastern Road, Hefei, Anhui 230031, P.R. China

E-mail: money2004@sina.com

*Contributed equally

Key words: esophageal squamous cell carcinoma, miR-155, chemoradio-resistance, DNA methylation, MAP3K10, JNK pathway migration and invasion of ESCC cells. By further screening its potential target genes, the present study identified MAP3K10 as the direct target gene to exert its anti-chemoradiation functions. The results also demonstrated that its differential expression pattern was negatively regulated by the methylation status of the upstream $\mathrm{CpG}$ island. Overall, the results of the present study demonstrated that miR-155-5p is a key molecule for understanding the heterogeneous responses of ESCC to chemoradiotherapy, and may be used in personalized treatment plans for this high mortality tumor in the future.

\section{Introduction}

Esophageal cancer is ranked as the ninth most commonly diagnosed cancer and the sixth leading cause of cancer-associated mortality worldwide, with an estimated 572,034 new cases $(3.2 \%$ of the total) and 508,585 deaths (5.3\% of the total) in 2018 (1). It has two main subtypes: Esophageal squamous cell carcinoma (ESCC) and esophageal adenocarcinoma (EAC), which are epidemiologically and biologically different. Although EAC is more common in the USA and several countries across Europe, ESCC is the predominant histology subtype of esophageal cancer globally, and occupies $>80 \%$ of cases of esophageal cancer (2). Currently, surgery is the definitive treatment method for early stage esophageal cancer. For those patients with advanced/unresectable tumors, neoadjuvant chemoradiotherapy has become the standard treatment option $(3,4)$. Even for those early stage patients, pre/post-operative chemoradiotherapy is also widely practiced in the clinical setting. Although some promising outcomes have been observed in clinic trials with neoadjuvant or adjuvant therapy (5-7), the overall 5-year survival of this disease still ranges from 15 to $25 \%$ (4), and resistance to chemoradiotherapy is one of the primary reasons for this. Thus, an 
improved understanding of the molecular mechanisms that affect tumor cell sensitivity to radiotherapy and chemotherapy would be beneficial for future personalized treatment plans to improve patient survival.

MicroRNAs (miRNAs/miRs) are a class of small noncoding RNAs that regulate gene expression at the post-transcriptional level, and play important roles in various biological processes, including the development of diseases (8). One of the most important tumor-promoting miRNAs is miR-155, which is processed from the B cell integration cluster (9). It has been revealed that aberrant expression of miR-155-5p presents as an oncogenic feature in several types of hematological malignancies and solid tumors (10-14), including ESCC $(15,16)$. It could promote cell proliferation, inhibit apoptosis, and induce EMT, invasion and migration, tumor metastasis and recurrence (17-19). Meta-analyses have demonstrated that miR-155 could be a potential biomarker for lung cancer detection (20), and the combined detection of multiple miRNA levels in ESCC tissues have significant prognostic values (21). However, conflicting studies have been published regarding the role of its dysregulation in radio- and chemo-resistance. For example, interference of $\mathrm{miR}-155-5 \mathrm{p}$ caused resistance to chemotherapy drugs and ionizing radiation in parental human epidermoid carcinoma cells (22) and breast cancer (23), respectively. However, the opposite behaviors have also been observed, indicating a greatly increased sensitivity to chemotherapy drugs $(11,24)$ and radiation $(25)$.

Given that there has been little data on the potential role of miR-155-5p in the radio- and chemo-resistance of ESCC cells, the present study determined the endogenous miR-155-5p expression levels and chemoradio-resistance profiles in ESCC cell lines. The results revealed that miR-155-5p was positively correlated with radio- and chemo-resistance. A systematic analysis was subsequently performed in order to reveal its role in response to radiation and drugs, and the underlying mechanism. The data generated in the present study are helpful for finding effective targets for ESCC chemo-radio sensitization.

\section{Materials and methods}

Cell culture and transfection. The human esophageal squamous cancer cell lines (KYSE-30, KYSE-140, KYSE-410, KYSE-450, KYSE-510 and TE-1), which were kindly provided by Professor Zhan (National Laboratory of Molecular Oncology), were cultured in RPMI-1640 medium plus $10 \%$ fetal bovine serum (cat. no. 10099-141; Thermo Fisher Scientific, Inc.) at $37^{\circ} \mathrm{C}$ in $5 \% \mathrm{CO}_{2}$. All cell lines were genetically authenticated using STR profiling by Genesky Biotechnologies, Inc.

Mimic/antagomiR/siRNA/plasmid DNA transfection. All mimics, antagomiR, siRNA and the scramble sequence control (NC), as well as riboFECT CP transfection kit (cat. no. C10511-05) were obtained from Guangzhou Ribobio Co., Ltd. Briefly, $4 \times 10^{5}$ cells were seeded into each well of 6-well plates and cultured overnight, and then they were transfected with $50 \mathrm{nM}$ mimic/siRNA, or $100 \mathrm{nM}$ antagomir using a riboFECT CP transfection kit. A total of $1.2 \mu \mathrm{g}$ of the GFP-tagged overexpression
MAP3K10 construct (cat no. HBLV-MAP3K10-GFP, Hanbio Biotechnology Co., Ltd.) was transfected into KYSE-410 cells using Attractene transfection reagent (cat no. 301005; Qiagen) according to the manufacturer's instructions. All transfections were carried out at room temperature, after which cells were cultured at $37^{\circ} \mathrm{C}$ for $24 \mathrm{~h}$. Then they were seeded into 96 -well or 6-well plates and underwent subsequent analysis $24 \mathrm{~h}$ later.

The siRNA sequences used for MAP3K10 interference in the present study were as follows $\left(5^{\prime} \rightarrow 3^{\prime}\right)$ : CCUGGAAACUGG UCUCCUUdTdT and dTdTGGACCUUUGACCAGAGGAA.

Clonogenic survival assay for radiation. ESCC cells in the exponential growth phase were seeded at a density of 250 ( $0 \mathrm{~Gy})$, 500 (1 Gy), 1,000 (2 Gy), 2,000 (4 Gy), 4,000 (6 Gy) cells/well on six-well plates in triplicate. After $24 \mathrm{~h}$ of incubation, adhesive cells were exposed to a 6 MV X-ray in CX-SN5340 (VARIAN) at 0 Gy, 1 Gy, $2 \mathrm{~Gy}, 4 \mathrm{~Gy}$ and $6 \mathrm{~Gy}$ with an average dose rate of $300 \mathrm{cGy} / \mathrm{min}$. After incubation for an additional 14 days, the cultures were fixed in methanol and stained with crystal violet. The number of colonies containing $>50$ cells were counted under a light microscope. The surviving fraction was calculated as previously described (26).

Chemoresistance profiling $\left(I_{50}\right.$ determination). Vinorelbine (Changchun Guoao Pharmaceutical Co., Ltd.), paclitaxel (Sichuan Taiji Pharmaceutical Co., Ltd.), docetaxel (Jiangsu Aokangsai Pharmaceutical Co., Ltd.), 5-flurorocil (Tianjin Jinyao Pharmaceutical Co., Ltd.), mitomycin (Zhejiang Haizheng Pharmaceutical Co., Ltd.), nedaplatin (Jiangsu Aokangsai Pharmaceutical Co., Ltd.) and cisplatin (Jiangsu Haosen Pharmaceutical Co., Ltd.) at the clinical-grade (NCI Dictionary of Cancer Terms, http://www.cancer.gov/dictionary) were used in the present study. Chemoresistance profiling ( $\mathrm{IC}_{50}$ measurements): Cells in the logarithmic growth phase were seeded in triplicate in 96-well plates at a density of $5 \times 10^{3} /$ well and treated with 4 -fold serially diluted drugs for $72 \mathrm{~h}$. Cell survival was then measured using a Cell Counting Kit-8-based (CCK-8; cat. no. B34302; Bimake) cell proliferation assay. $\mathrm{The} \mathrm{IC}_{50}$ (the concentration of drug required for $50 \%$ of the cells to be killed) was calculated with the no-drug control as the reference.

Cell proliferation assay. Cells in the logarithmic growth phase were seeded in 96-well plates at a cell density of $2 \times 10^{3} /$ well (in triplicate) to allow adhesion. At $0,24,48,72$ and $96 \mathrm{~h}$, cells were incubated with $10 \mu \mathrm{lCCK}-8$ at $37^{\circ} \mathrm{C}$ for an extra $2 \mathrm{~h}$. The optical density was then measured with a microplate reader (Tecan Group Ltd.) at $450 \mathrm{~nm}$. The cells were then cultured with fresh medium until the next round of measurements. The mean and standard deviation of the triplet measurements were calculated and plotted.

Wound-healing assay. Confluent cells were serum-starved in RPMI-1640 medium for 10-12 $\mathrm{h}$ and scratched using the tip of a $10-\mu 1$ pipette. After being washed twice with PBS to remove non-adherent cells, the plates were changed to $500 \mu \mathrm{l}$ RPMI-1640 medium plus 10\% FBS. The wound area was photographed at 0 and $22 \mathrm{~h}$ under an Olympus IX73 inverted microscope. A cell-free region was drawn and measured by CellSens Standard software (Olympus). The average and 
standard deviation were calculated from no less than three different wounds from one of three attempts.

Invasion assay. A BioCoat ${ }^{\mathrm{TM}}$ Matrigel invasion chamber (cat. no. 40480; BD Biosciences) was used according to the manufacturer's protocol. Briefly, $4 \times 10^{4}$ cells were trypsinized, washed, suspended in $200 \mu \mathrm{l}$ serum-free RPMI-1640 medium, and seeded in the upper portion of the invasion chamber. The lower portion of the chamber contained $500 \mu \mathrm{l}$ of RPMI-1640 medium plus $10 \%$ FBS, which served as a chemo-attractant. After $36 \mathrm{~h}$, the non-invasive cells were removed from the upper surface of the membrane with a cotton swab. The invasive cells on the lower surface of the membrane were stained with $0.1 \%$ crystal violet for $30 \mathrm{~min}$ at room temperature, and counted in four separate areas with an inverted microscope.

miRNA target prediction. Two miRNA target prediction and functional study databases, TargetScan (http://www.targetscan. org/) and miRDB (http://mirdb.org/), were employed to search for the potential targets of miR-155-5p. The overlapped targets were selected for further validation.

Luciferase reporter assay. A full length of the human MAP3K10 3'-UTR region (284 bp) with the miR-155-5p targeting sequence was cloned at the downstream region of the firefly luciferase gene in the pGL3-basic vector (cat. no. E1751; Promega Corporation) to construct pGL3-luc-MAP3K10.

Cells were seeded into 96 -well plates at $\sim 1 \times 10^{4}$ cells/well and transfected with a mixture of $100 \mathrm{ng}$ pGL3-luc-MAP3K10, 10 ng Renilla plus 5 pmol mimic or scrambled control (NC) nucleotides, with the riboFECT CP transfection reagents according to the manufacturer's protocol. Both firefly and Renilla luciferase activities were assessed $18 \mathrm{~h}$ after transfection by the Dual-Luciferase Reporter Assay system (cat. no. E1910; Promega Corporation) using a Promega GloMax 20/20 luminometer. The relative firefly luciferase activities of the UTR constructs and C-Jun N-terminal kinase (JNK) pathway reporter constructs (cat. no. CCA-901L; Qiagen) were analyzed as previously described (27).

Reverse transcription-quantitative PCR (RT-qPCR). Total RNA was isolated from the cells at the logarithmic growth phase using TRNzol-A+ reagent (cat. no. DP421; Tiangen Biotech Co., Ltd.), and $1 \mu \mathrm{g}$ RNA was converted to cDNA with a 100-nM mixture of miR-155 specific stem-loop primer and U6 specific reverse primers (synthetized by ShingGene) using the HiScript II 1st Strand cDNA Synthesis kit (cat. no. R211-01; Vazyme) for a $20-\mu 1$ reaction. The steady state of the miR-155-5p and U6 was simultaneously quantified using a dual-RT-qPCR assay with the differentially fluorescent-labeled TaqMan probes for miR-155-5p (FAM) and U6 (HEX) (ShingGene) and a FTC-3000P PCR instrument (Funglyn Biotech, Inc.). Briefly, $3.125 \mathrm{mM} \mathrm{Mg}^{2+}, 0.2 \mathrm{mM}$ dNTP, $6.25 \mathrm{U}$ Hotstart Taq DNA polymerase, $1 \mu \mathrm{M}$ Forward Primer, $1 \mu \mathrm{M}$ Reverse Primer and $0.2 \mu \mathrm{M}$ TaqMan Probe were used for each round of RT- PCR. The conditions used were as follows: $95^{\circ} \mathrm{C}$ for $5 \mathrm{~min}$, followed by 40 cycles at $95^{\circ} \mathrm{C}$ for $15 \mathrm{sec}$, and $60^{\circ} \mathrm{C}$ for $1 \mathrm{~min}$ (28). The relative expression level of miR-155-5p was normalized to U6 using the $\Delta \Delta \mathrm{Cq}$ method (29). The sequences of the primers and probes were listed as follows $\left(5^{\prime} \rightarrow 3^{\prime}\right)$ : miR-155-5p RT, GCG
CGTGAGCAGGCTGGAGAAATTAACCACGCGCACCCC, miR-155-5p forward, TCGTTAATGCTAATCGTG, reverse, GAGCAGGCTGGAGAA and probe, FAM-ACCACGCGC ACCC; U6 forward, CTCGCTTCGGCAGCACATA, RT and reverse, CGCTTCACGAATTTGCGTG and probe, HEX-CCT TGCGCAGGGGCCATGC.

Western blot analysis. Cells were lysed in a solution of $60 \mathrm{mM}$ Tris- $\mathrm{HCl}, \mathrm{pH} 6.8,2.00 \%$ sodium dodecyl sulfate, $20.00 \%$ glycerol, $0.25 \%$ bromophenol blue, $1.25 \%$ 2-mercaptoethanol and heated at $100^{\circ} \mathrm{C}$ for $10 \mathrm{~min}$. Protein concentrations were determined using a BCA protein assay kit. After being separated by 10 or $12 \%$ SDS-PAGE, the protein $(40-50 \mu \mathrm{g})$ was transferred to a PVDF membrane (cat. no. IPVH00010; EMD Millipore). The membranes were blocked in 1X PBS buffer containing 5\% BSA (cat. no. A1933; Sigma-Aldrich; Merck KGaA) and 0.05\% Tween-20 (cat. no. A100777; Sangon Biotech Co., Ltd.) for $1 \mathrm{~h}$ at room temperature, and then incubated with the following primary antibodies: $\gamma-\mathrm{H} 2 \mathrm{AX}$ (rabbit anti-human monoclonal; 1:1,000; cat. no. 9718; Cell Signaling Technology, Inc.); H2AX (rabbit anti-human polyclonal; 1:1,000; cat. no. 10856-1-AP); Lamin B1 (rabbit anti-human polyclonal; 1:1,000; cat. no. 12987-1-AP); RAD51 (rabbit anti-human polyclonal; 1:1,000; cat. no. 14961-1-AP); and Ku80 (rabbit anti-human polyclonal; 1:1,000; cat. no. -1-AP; all from ProteinTech Group, Inc.); MAP3K10 (sheep anti-human polyclonal; 1:1,000; cat. no. AF5066; R\&D Systems); GAPDH (mouse anti-human monoclonal; 1:2,000; cat. no. 60004-1-Ig); and $\alpha$-tubulin (mouse anti-human monoclonal; 1:2,000; cat. no. 11224-1-AP; both from ProteinTech Group, Inc.) overnight at $4^{\circ} \mathrm{C}$. The blots were washed with PBST three times for $10 \mathrm{~min}$ each and incubated with secondary antibodies anti-rabbit $\operatorname{IgG}$ (1:3,000; cat. no. SA00001-2); and anti-mouse IgG (1:3,000, cat. no. SA00001-1; both from ProteinTech Group, Inc.; and anti-sheep IgG, 1:1,000, cat. no. HAF016, $\mathrm{R} \& \mathrm{D}$ Systems) for $1 \mathrm{~h}$ at room temperature. The target bands were revealed by SuperSignal West Pico PLUS chemiluminescence substrate (cat. no. 34580; Thermo Fisher Scientific, Inc.), and the relative density of each protein over Lamin B1, GAPDH or $\alpha$-tubulin was quantified using a Gel-Pro Analyzer 3.1 (Media Cybernetics).

5-Aza-2'-deoxycytidine treatment. KYSE-140 and KYSE-30 cells were treated with $50 \mathrm{mM} 5$-aza-2'-deoxycytidine (5-aza-dC; cat. no. A3656; Sigma-Aldrich; Merck KGaA) for $72 \mathrm{~h}$ with a change of culture medium every $24 \mathrm{~h}$ as previously described (30).

BSP analysis. Genomic DNA was isolated using a PureGenome $^{\mathrm{TM}}$ kit (cat. no. P-9040-M; Aline Bioscience) and quantitated via electrophoresis on an agarose gel. The bisulfate conversion was achieved using an EZ DNA Methylation-Gold kit (cat. no.D5006; ZYMOResearch). The CpG island upstream of miR-155 gene was amplified by two pairs of primers. The sequences of the primers were listed as follows $\left(5^{\prime} \rightarrow 3^{\prime}\right)$ : 1 st forward, GTTTGGTYGGTTATGAGTTATAAGTGAG and reverse, CAAAAACRTCTCCTTAATTCCCC; 2nd forward AAGGAGAYGTTTTTGGTATTGTAGG and reverse, GAC ACCACTAAATCCCCAAAAAAC. Briefly, $500 \mathrm{nM}$ of each primer, $4 \mathrm{mM}$ dNTP, $2 \mathrm{mM} \mathrm{MgCl}{ }_{2}, 6.25$ U Hotstart Taq DNA 
A

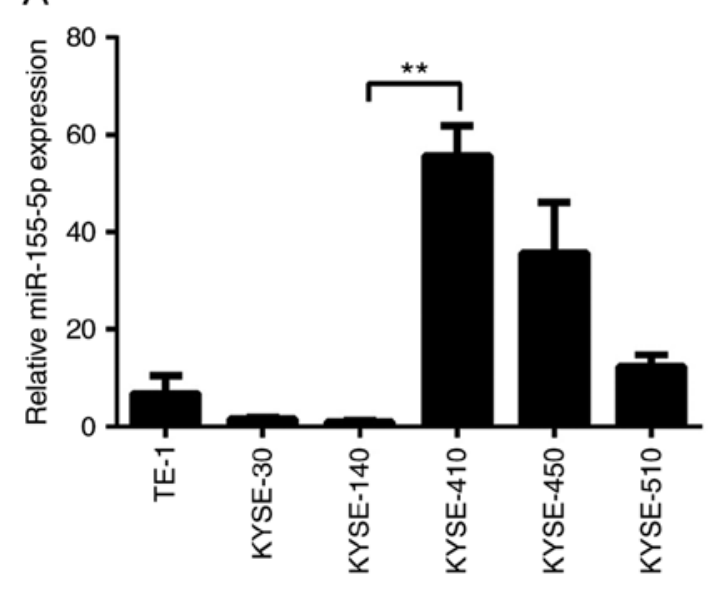

$\mathrm{B}$

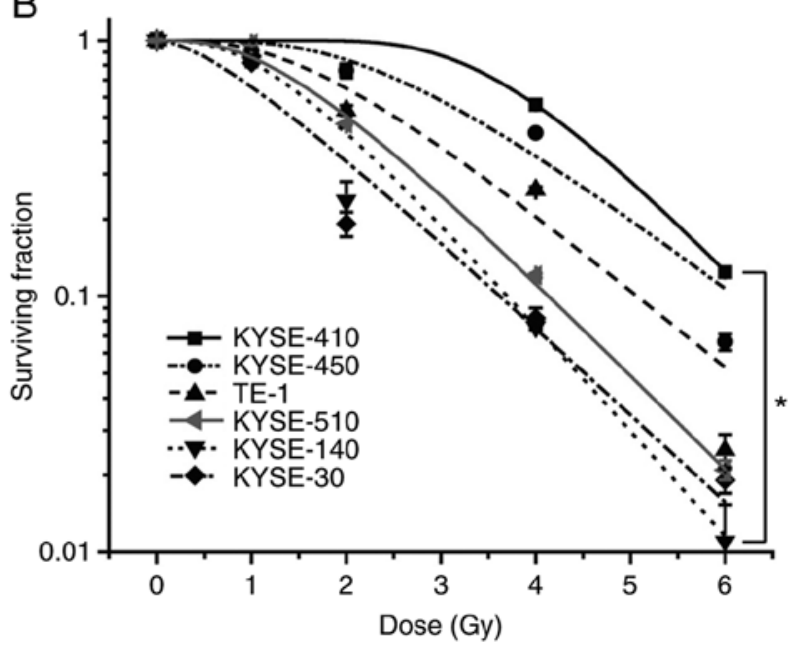

Figure 1. High expression of miR-155-5p is associated with radioresistance in ESCC cells. (A) Differential expression of miR-155-5p in ESCC cell lines. Its expression level was determined by dual-TaqMan RT-qPCR with the lowest expression level in KYSE-140 and highest expression level in KYSE-410 cells (B) A clonogenic survival assay demonstrating the radio-response of six ESCC cell lines. Cells were inoculated in the 6-well plates and exposed to 0, 1,2, 4 and 6 Gy of radiation, and then cultured for 14 days, living cells formed clones that were counted. Dose survival curves were created by fitting surviving fractions to the linear quadratic equation. ${ }^{*} \mathrm{P}<0.05$ and ${ }^{* *} \mathrm{P}<0.001$. ESCC, esophageal squamous cell carcinoma.

polymerase and 2\% DMSO were used for each round of PCR. The conditions used were as follows: $95^{\circ} \mathrm{C}$ for $10 \mathrm{~min}$, followed by 40 cycles at $95^{\circ} \mathrm{C}$ for $15 \mathrm{sec}$, and $60^{\circ} \mathrm{C}$ for $1 \mathrm{~min}$. The PCR fragments from the converted DNA were cloned and verified by sequencing as previously described (31).

Online data for gene expression in esophageal cancer. A ESCC cohort from The Cancer Genome Atlas (TCGA) was included for survival rate analysis using Kaplan-Meier survival analysis. Oncomine database (https://www.oncomine.org/resource/login.html) was used to mine the data of MAP3K10 gene expression in ESCC and EAC.

Statistical analysis. Data are presented as the means, and error bars indicate the standard deviation (SD). All statistical analyses were performed with Excel (Microsoft, Inc.) or GraphPad Prism 6 (GraphPad Software Inc.). One-way ANOVA followed by Dunnett's post hoc test and two-tailed Student's $t$-test were used to calculate statistical significance. A P-value of $<0.05$ was considered to indicate a statistically significant difference.

\section{Results}

miR-155-5p is differentially expressed in ESCC cells and positively associated with radioresistance. The expression level of miR-155-5p was examined in six ESCC cell lines via RT-qPCR (Fig. 1A). The results revealed that the expression of miR-155-5p varied among the different cells, with KYSE-410 cell expression $\sim 55.3$-fold higher than KYSE-140 cells. As radiotherapy is widely applied to patients with ESCC and has a central role in the therapeutic strategy against ESCC, the sensitivity of six ESCC cell lines to radiation was then evaluated using a clonogenic survival assay (Fig. 1B). The surviving fraction of KYSE-410 cells was greater than that of the other five cell lines, indicating that KYSE-410 was the most radioresistant, whereas, KYSE-30 and KYSE-140 presented with the highest radiosensitivity. These indicated a positive association between radioresistant capacity and the expression of miR-155-5p in ESCC cells. Thus, KYSE-140 (the most radiosensitive cells whose miR-155 was the lowest) and KYSE-410 (the most radioresistant cells whose miR-155 is the highest) were selected cell lines for the following study.

miR-155-5p renders ESCC cells resistant to radiation by repairing the DNA damage more efficiently. In order to investigate the role of miR-155-5p in the radiotherapy response of ESCC cells, the present study ectopically expressed miR-155-5p and the corresponding control scrambled RNA in radiosensitive KYSE-140 cells, which were then irradiated after seeding on cell culture plates for clonogenic survival assays. Following overexpression of miR-155-5p to $>300$-fold (Fig. 2A), the survival rate of the mimic-transfected KYSE-140 cells at each dose was higher than that of NC (Fig. 2C), indicating that miR-155-5p enhanced radioresistance. Conversely, silencing of miR-155-5p to $20 \%$ in KYSE-410 cells (Fig. 2B) decreased the cell survival rate against radiation (Fig. 2D), indicating that inhibition of miR-155 sensitized ESCC cells to radiation.

It has previously been proposed that ionizing radiation damages tumor cells through several mechanisms, mainly by DNA damage, particularly double-strand breaks (DSBs) $(32,33)$. Cell survival following DNA damage relies on DNA repair, the abrogation of which causes genomic instability and cell death. In order to confirm that a defect in the repair of DSBs is involved in the radioresistance mediated by miR-155-5p in ESCC cells, cells were exposed to X-rays at $4 \mathrm{~Gy}$ in the present study. The expression level of phosphorylated histone family member $\mathrm{X}(\gamma-\mathrm{H} 2 \mathrm{AX})$, which is a powerful biomarker to monitor DSBs in cells (34), was detected at various time-points after radiation. Significant induction of $\gamma-\mathrm{H} 2 \mathrm{AX}$ was observed at $0.5 \mathrm{~h}$ after radiation compared to the cells without radiation. It decreased more rapidly from $6 \mathrm{~h}$ post-radiation in miR-155-5p overexpressing-KYSE-140 cells, compared to the NC group. Conversely, the level of $\gamma-\mathrm{H} 2 \mathrm{AX}$ 

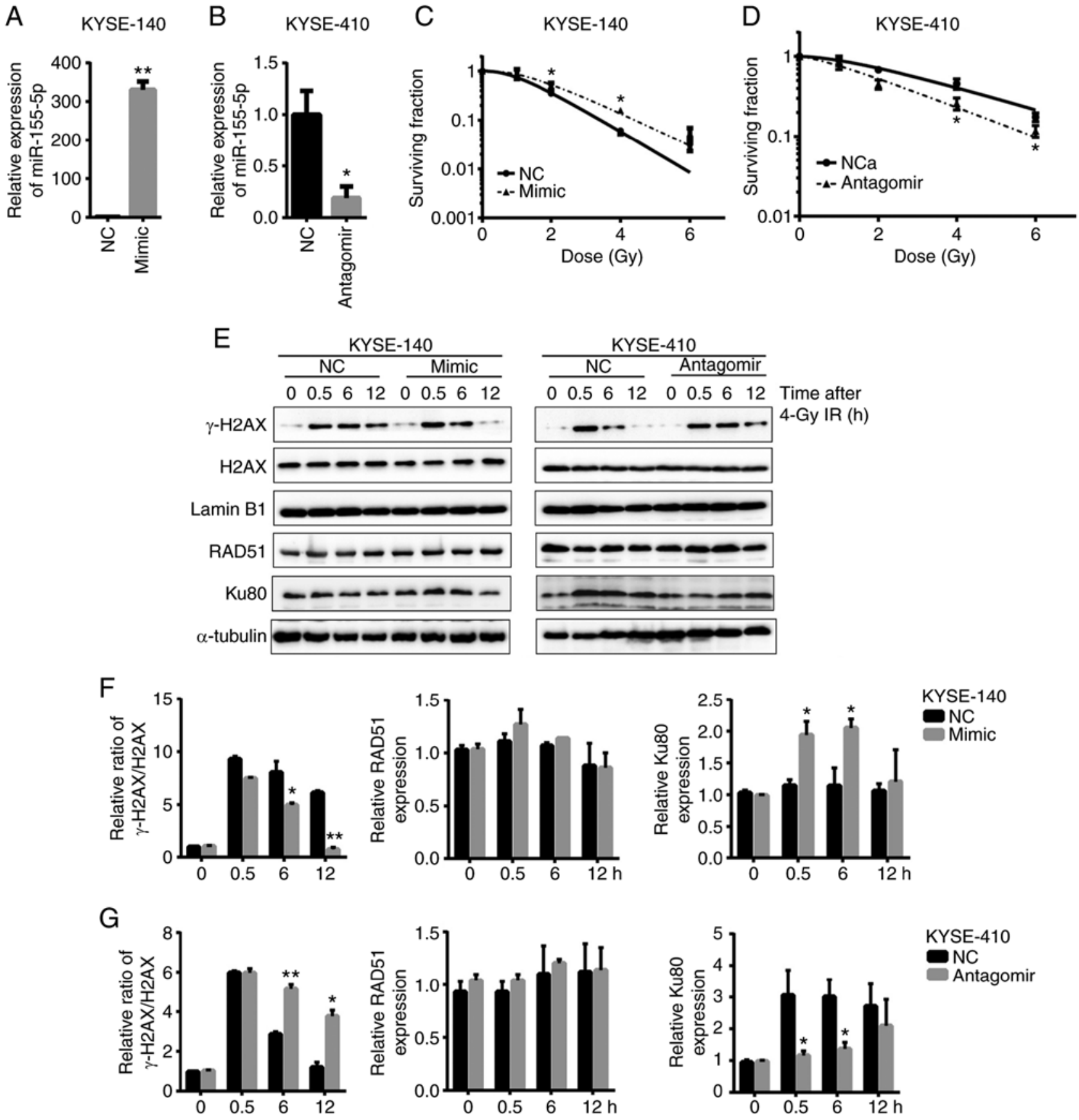

Figure 2. Increased miR-155-5p expression renders ESCC cells resistant to radiation. (A and B) The level of miR-155-5p in the mimic-transfected KYSE-140 cells and the antagomir-transfected KYSE-410 cells vs. the non-specific control (NC) was determined by dual-TaqMan RT-qPCR (C and D) miR-155-5p mimic-transfected KYSE-140 cells increased the survival fraction, while miR-155-5p antagomir-transfected KYSE-410 cells decreased the survival fraction when compared with the NC cells. (E) The level of proteins concerning DNA damage and repair was examined via western blotting. Cells were transfected with miR-155 mimic/antagomir $48 \mathrm{~h}$ before exposure to $4 \mathrm{~Gy}$ radiation and then harvested at $0,0.5,6,12$-h time-points. All experiments were repeated at least 3 times. (E-G) The protein levels of $\gamma-\mathrm{H} 2 \mathrm{AX}$ and $\mathrm{H} 2 \mathrm{AX}$ were digitized and normalized with Lamin B1, then the ratio of $\gamma-\mathrm{H} 2 \mathrm{AX} / \mathrm{H} 2 \mathrm{AX}$ was calculated. In addition, the protein levels of RAD51 and Ku80 were digitized with $\alpha$-tubulin (arbitrarily as 1) in (F) mimic-transfected KYSE-140 cells and $(\mathrm{G})$ antagomir-transfected KYSE-410 cells were compared with the control groups and plotted. ${ }^{*} \mathrm{P}<0.05 ;{ }^{* *} \mathrm{P}<0.001$. ESCC, esophageal squamous cell carcinoma.

decreased more slowly in the anti-miR-155-5p KYSE-410 cells from $6 \mathrm{~h}$ after radiation, compared to the $\mathrm{NC}$ group (Fig. 2E-G). This revealed that there was an early onset and high capacity of DNA repair by upregulation of miR-155-5p.

DSB induced in mammalian cells is repaired by two repair pathways. One is non-homologous end joining (NHEJ), the other is homologous recombination (HR). Deficiency in proteins involved in the DNA damage repair is considered a major determinant of response to radiotherapy and chemotherapy (35). Thus, the present study investigated whether increased expression and/or activity of DNA repair proteins confer resistance to radiation. The protein levels of RAD51 and $\mathrm{Ku} 80$, the key components of HR and NHEJ, respectively, were examined. The results revealed the expression of Ku80 was increased from $0.5 \mathrm{~h}$ after radiation in the miR-155-5p mimic-transfected KYSE-140 cells, but it remained almost 
unchanged in the $\mathrm{NC}$ group. Consistently, accumulation of $\mathrm{Ku} 80$ occurred at $0.5 \mathrm{~h}$ after radiation in KYSE- 410 cells, but its level was significantly lower in anti-miR-155 KYSE-140 cells compared to the NC group (Fig. 2E-G). Thus, NHEJ rather than HR played a major role in repairing the DSB induced by radiation in ESCC cells. Collectively, miR-155-5p promoted DNA damage repair and induced resistance against radiation via upregulation of Ku80 and activation of NHEJ repair.

Increased expression of miR-155-5p promotes multi-drug resistance in ESCC cells. Generally, resistance occurs not only to radiation but also to traditional chemotherapeutic drugs in cancer cells. Thus, the present study performed drug-resistance profiling in two cell lines against the following drugs: Paclitaxel, docetaxel, vinorelbine, cisplatin, nedaplatin, mitomycin and 5 -fluorouracil. The dose required for the $\mathrm{IC}_{50}$ after a treatment of $72 \mathrm{~h}$ was determined. In agreement with the radio-resistance profiles, KYSE-410 cells were more resistant to multi-drugs than KYSE-140 cells (Fig. 3A), which indicated that miR-155-5p was also involved in the chemo-resistance of ESCC cells.

In order to demonstrate its role in the ESCC chemoresistance, the present study examined the drug-induced cell death in mimic/antagomiR-transfected cells. The results revealed that introducing miR-155-5p increased the cell viability of KYSE-140 cells after treatment with vinorelbine, cisplatin, paclitaxel and docetaxel (Fig. 3B). Conversely, knockdown of miR-155-5p sensitized KYSE-410 cells to 5-flourouracil, vinorelbine, cisplatin and docetaxel (Fig. 3C). Therefore, miR-155-5p enhanced ESCC cell resistance to vinorelbine, cisplatin and docetaxel in a drug-specific manner.

miR-155 enhances migration, invasion and proliferation of ESCC cells. The present study further investigated whether miR-155-5p interfered with the potential motility and proliferation of ESCC cells. A marked positive correlation between the expression of miR-155-5p and the motility of ESCC cells was observed. Following overexpression of miR-155, KYSE-140 cells migrated 1.8-fold faster than the control groups (Fig. 4A and B). In contrast, miR-155-5p downregulation decreased the migratory speeds of KYSE- 410 cells by $\sim 50 \%$ (Fig. 4A and B). Additionally, the number of invaded cells were increased in the miR-155-5p-overexpressing KYSE-140 cells and decreased in anti-miR-155-5p KYSE-410 cells (Fig. 4C and D), confirming the promoting role of miR-155-5p in motility. Furthermore, the present study demonstrated that the proliferation, quantified by a CCK-8 assay over a period of 4 days, was increased in mimic-transfected KYSE-140 cells (Fig. 4E) and decreased in antagomir-transfected KYSE-410 cells compared with the control groups (Fig. 4F). All these data indicated that in addition to radio- and chemo-resistance, miR-155-5p also contributed to high migration and invasion capacities and an increased proliferation rate in ESCC cells, confirming the oncomiR role of miR-155-5p. Consistently, by analyzing the survival rate of a ESCC cohort form TCGA, we found that high expression of miR-155-5p was associated with poor overall survival in patients with ESCC (Fig. S1).

DNA methylation around the transcription start site of miR-155HG exhibits differences in ESCC cell lines and
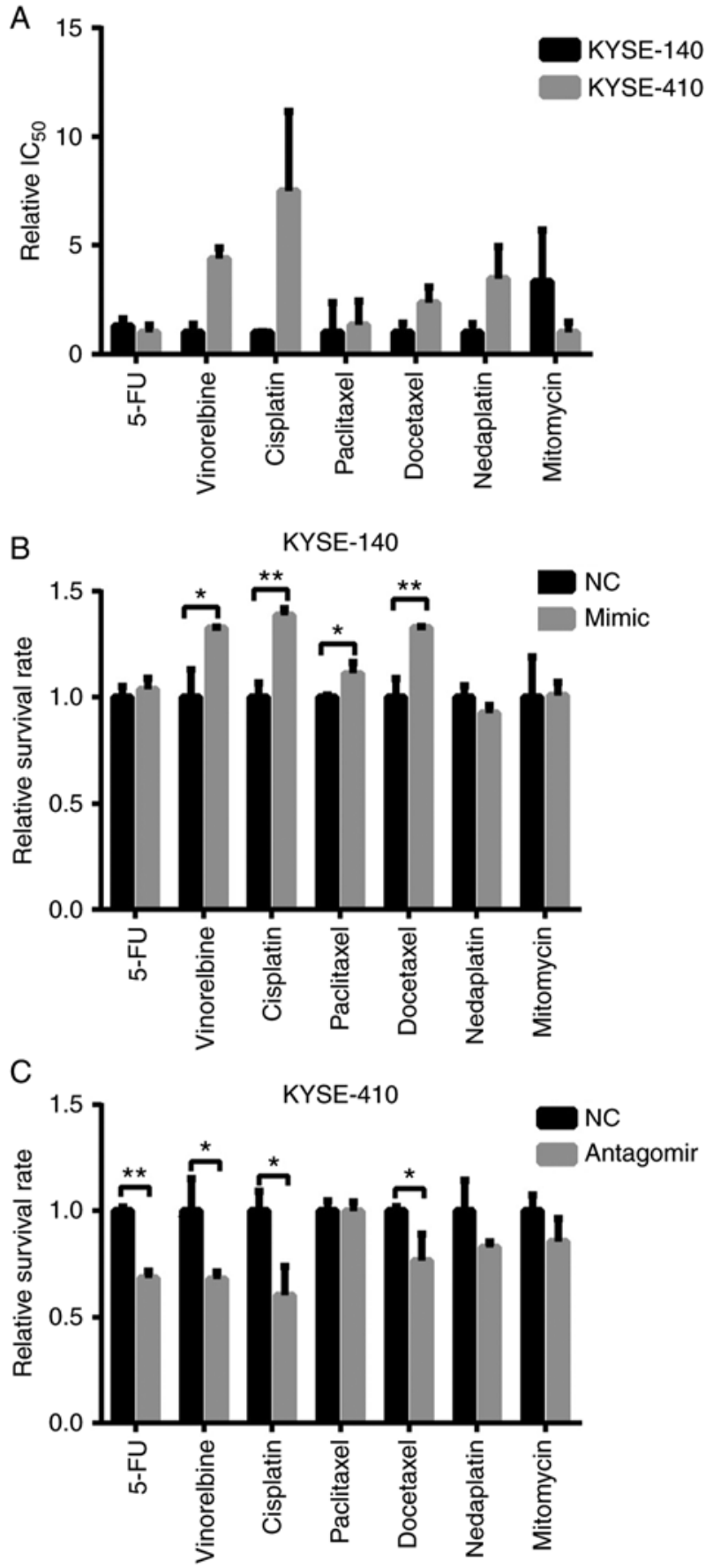

Figure 3. Increased expression of miR-155-5p promotes multi-drug resistance in ESCC cells. (A) Chemo-sensitivity profiles of KYSE-140 and KYSE-410 cells to seven chemotherapeutic drugs. Cells were seeded in 96-well plates and treated with 4-fold serially diluted drugs for $72 \mathrm{~h}$. Cell survival was then measured using a CCK-8-based cell proliferation assay. (B) The relative cell survival of the KYSE-140 cells transfected by miR-155-5p mimic over the NC transfected cells, $72 \mathrm{~h}$ after a treatment of the $\mathrm{IC}_{50}$ dosed drugs. (C) The $\mathrm{IC}_{50}$ dosed drugs triggered cell death in the miR-155-5p antagomiR- vs. the NC-transfected KYSE-410 cells. " $\mathrm{P}<0.05$ and ${ }^{* *} \mathrm{P}<0.001$. ESCC, esophageal squamous cell carcinoma.

is negatively correlated with the expression of miR-155. miR-155 is encoded by the non-protein-coding BIC gene (now designated, MIR155 host gene or MIR155HG). MIR155HG promoter sequence and the first exon harbor a $\mathrm{CpG}$ island (CGI) containing $51 \mathrm{CpGs}$ (Fig. 5A). In order to elucidate the mechanisms implicated in the regulation of miR-155 expression, the present study hypothesized that the DNA methylation 
A

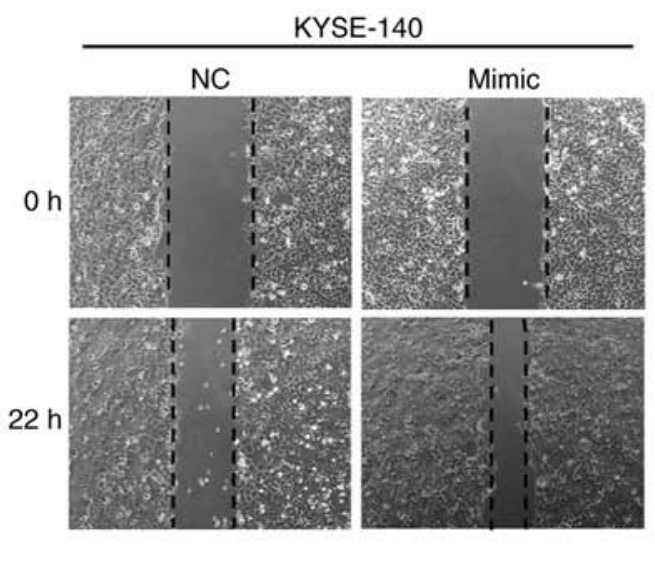

C
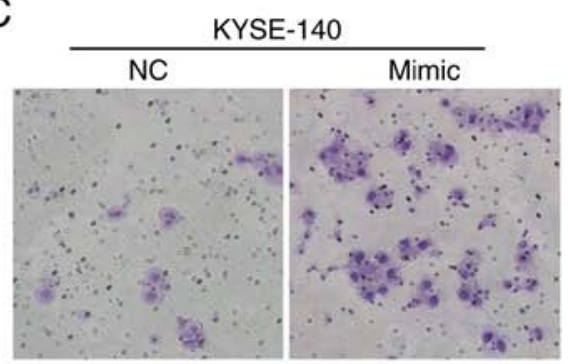

E

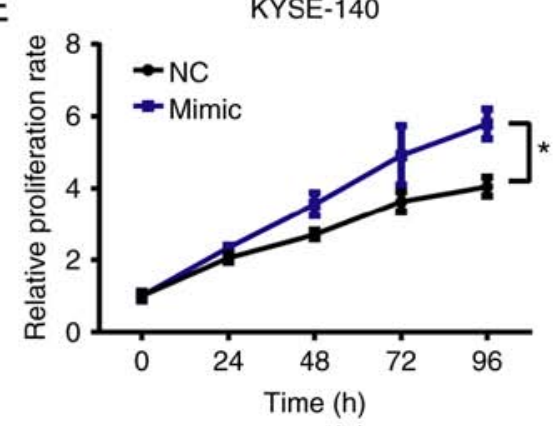

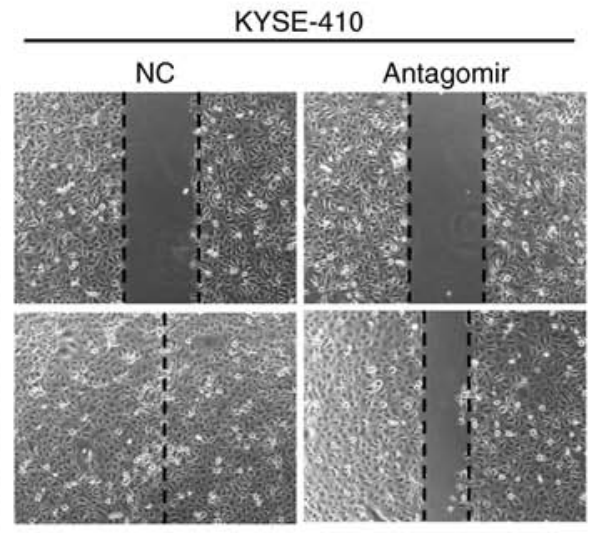

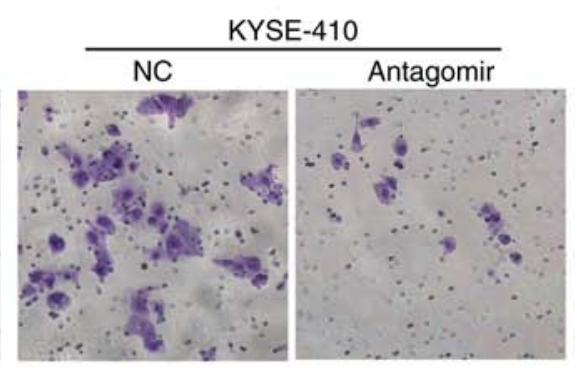

$\mathrm{F}$

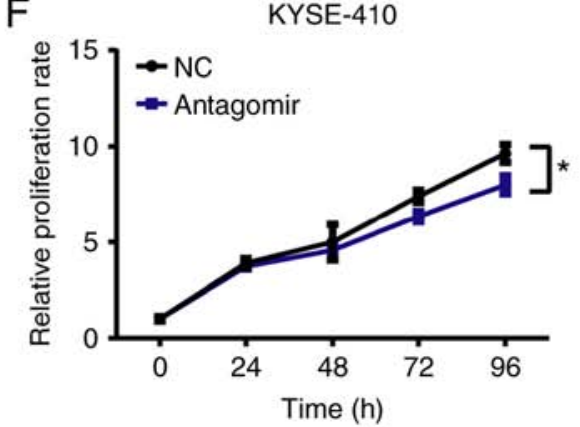

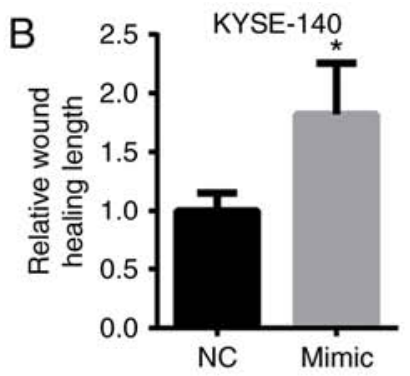

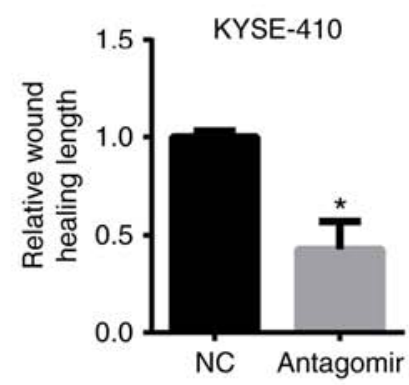

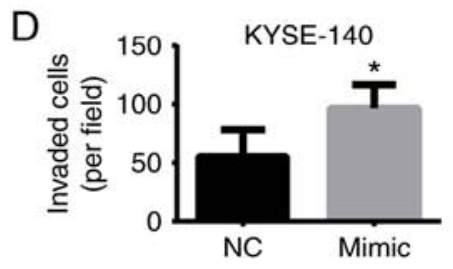

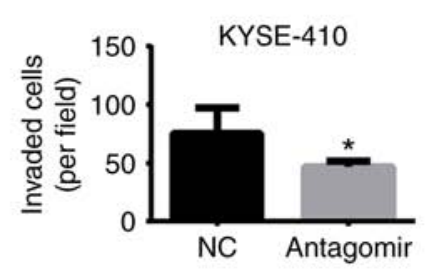

Figure 4. Effects of the ectopic expression of miR-155 on the migration, invasion and proliferation of ESCC cells. (A and B) ESCC cells were subjected to the indicated mimic and antagomir RNAs, and the wound healing state of three replicates were recorded at 0 and $22 \mathrm{~h}$ under an inverted microscope. The mean \pm standard deviation $(n=3)$ of the migrated cell ratio between the measurements at 0 and the $22 \mathrm{~h}$ was plotted. $(\mathrm{C}$ and $\mathrm{D})$ The cell invasion activity was determined with a Boyden chamber Transwell assay. The mean \pm standard deviation of five randomly selected fields were determined and plotted. These images are representative of one experiment and statistical analysis was performed using data from three independent experiments. (E and $\mathrm{F}$ ) The proliferation of the cells was evaluated via CCK-8 following transfection with the indicated (E) miR mimics and (F) antagomir at $24,48,72$ and $96 \mathrm{~h}$. ${ }^{*} \mathrm{P}<0.05$. ESCC, esophageal squamous cell carcinoma.

status of CpGs, which is the best-characterized epigenetic mechanism (36), may be involved in the regulation of miR-155 expression levels. A bisulfite conversion sequencing (BSP) analysis of this region was performed. Two pairs of primers were used to amplify the $45 \mathrm{CpG}$ sites in the CGI. The results revealed that DNA methylation differed among the six cell lines. CGI was hypermethylated in KYSE-140 and KYSE-30 cells, moderately methylated in KYSE-510 and TE-1 cells, but barely methylated in KYSE-410 and KYSE-450 cells (Fig. 5B and C). To further confirm the transcriptional repression of miR-155 by DNA methylation, the methylase inhibitor 5 -zaz-dC was used in the present study. After treatment with 5-aza-dC, the expression of miR-155-5p was increased by $>3$-fold in the KYSE-140 and KYSE-30 cells (Fig. 5D). In addition, evaluation of DNA methylation status revealed that the two cell lines exhibited a partially demethylated pattern in the CpG island upstream of the miR-155 gene (Fig. 5E). In conclusion, the transcription of miR-155 gene was repressed by DNA methylation of the MIR155HG promoter.

MAP3K10 is the target gene of miR-155 in ESCC cells. The present study assessed the level of overlapped predicted target genes of miR-155-5p in the Arraystar datasets (data not shown) of KYSE-140 and KYSE-410 cells. MAP3K10 was observed to be expressed in an opposite manner to miR-155-5p. Further RT-qPCR and western blot analyses demonstrated that the protein level of MAP3K10 was significantly higher in the KYSE-140 than that in the KYSE-410 cells (western blot analysis, 1.00:0.51; Fig. 6A). Furthermore, miR-155-5p mimic transfection decreased the levels of MAP3K10 by $260 \%$ in 
A

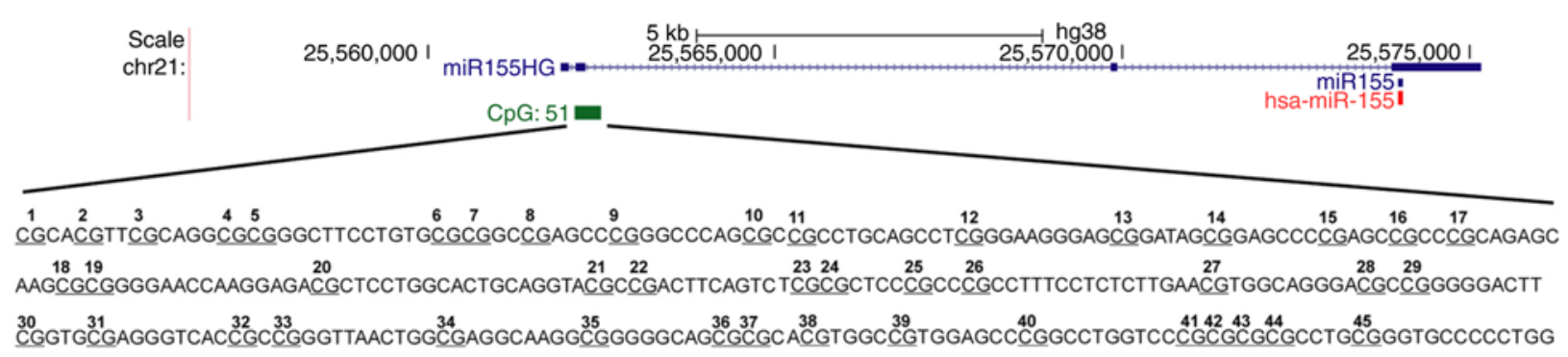
GGACTCAGTGGTGTCGCCTCGCCCGGGACCAGAGATTGCGCTGGATGGATTCCCGC

B

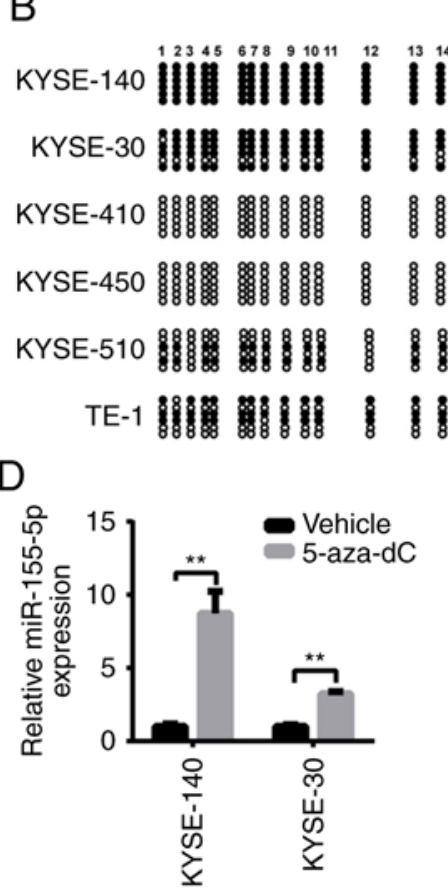

C

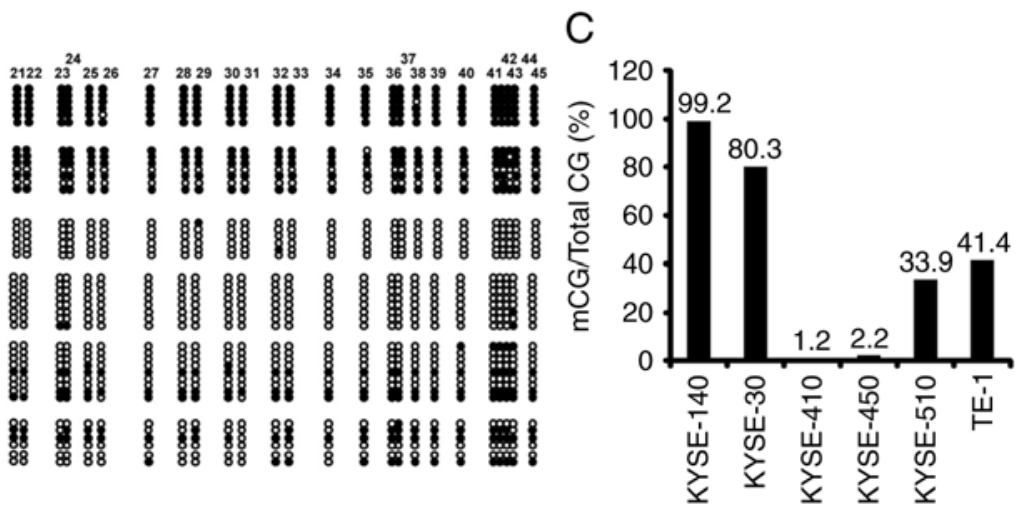

E

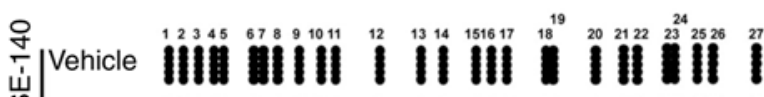

2829

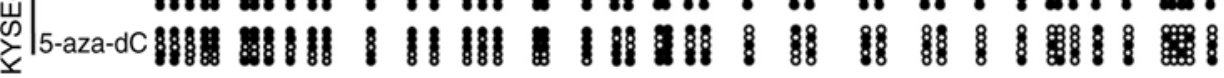

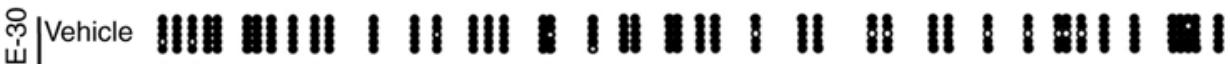
它

Figure 5. Differential expression levels of miR-155-5p are negatively regulated by the methylation status of CpG islands upstream of the miR-155 gene in ESCC cells. (A) A schematic representing the location of miR-155 and its host gene MIR155HG in the genome from the UCSC website. The physical map of the CpG island, a 382-bp region containing 51 CpGs analyzed by BSP are indicated. (B) DNA methylation state of the miR-155 gene in each of six ESCC cell lines was determined by BSP. Altogether 45 out of $51 \mathrm{CpGs}$ were examined. The filled and open circles refer to the methylated and unmethylated CpGs, respectively. (C) All the data of B are summarized. (D) miR-155-5p was upregulated in the indicated ESCC cell lines following treatment with 5-aza-dC for 72 h. (E) DNA methylation status of $45 \mathrm{CpG}$ sites upstream of miR-155 gene after $72 \mathrm{~h}$ of 5-aza-dC treatment. ESCC, esophageal squamous cell carcinoma; BSP, bisulfite sequencing PCR; 5-aza-dC, 5-aza-2'-deoxycytidine. ${ }^{* *} \mathrm{P}<0.001$.

KYSE-140 cells, and its level was increased by $\sim 2.3$-fold in the antagomiR-transfected KYSE-410 cells (Fig. 6B).

For confirmation that MAP3K10 is the direct target of miR-155-5p, its 3'-UTR regions were placed downstream of the firefly luciferase gene in pGL3 (Promega Corporation) to create the pGL3-MAP3K10 UTR construct (Fig. 6C). Both pGL3-MAP3K10 UTR and pGL3 were transfected into KYSE-140 and KYSE-410 cells, in order to observe the functionalstate of miR-155-5pin these cells.pGL3-MAP3K10-UTR, but not pGL3, produced a 1.5-fold higher luciferase activity in KYSE-140 than in KYSE-410 cells, in an opposite pattern of miR-155-5p expression (Fig. 6D). Furthermore, the luciferase activity of pGL3-MAP3K10-UTR WT was decreased by $45 \%$ in the mimic-transfected KYSE-140 cells (Fig. 6E) and increased by $50 \%$ in the antagomiR-transfected KYSE-410 cells, but not in the pGL3-transfected control (Fig. 6F). Collectively, MAP3K10 is in fact a direct target of miR-155-5p and may execute its effect on ESCC radio- and chemo-resistance.
MAP3K10 suppresses radio- and chemo-resistance of ESCC. In order to investigate the role of MAP3K10, siRNA transfection-mediated knockdown of MAP3K10 was performed in KYSE-140 cells in the present study. The expression of MAP3K10 was decreased to $28 \%$ by siRNA at the protein level (Fig. 7A). Suppression of MAP3K10 not only increased the cell viability when compared with the control groups after exposure to radiation (Fig. 7B), but also significantly desensitized KYSE-140 cells to the cell death triggered by vinorelbine and cisplatin (Fig. 7C). Conversely, overexpression of MAP3K10 in KYSE-410 cells (Fig. 7D) decreased resistance against radiation (Fig. 7E) and drugs (Fig. 7F). In contrast to the effect imposed by the miR-155a-5p mimic, both MAP3K10 knockdown and overexpression failed to cause a significant change of sensitivity to docetaxel, which indicated that other target genes of miR-155-5p may participate in this process.

Furthermore, the present study also observed that the proliferation of ESCC cells was suppressed by MAP3K10 

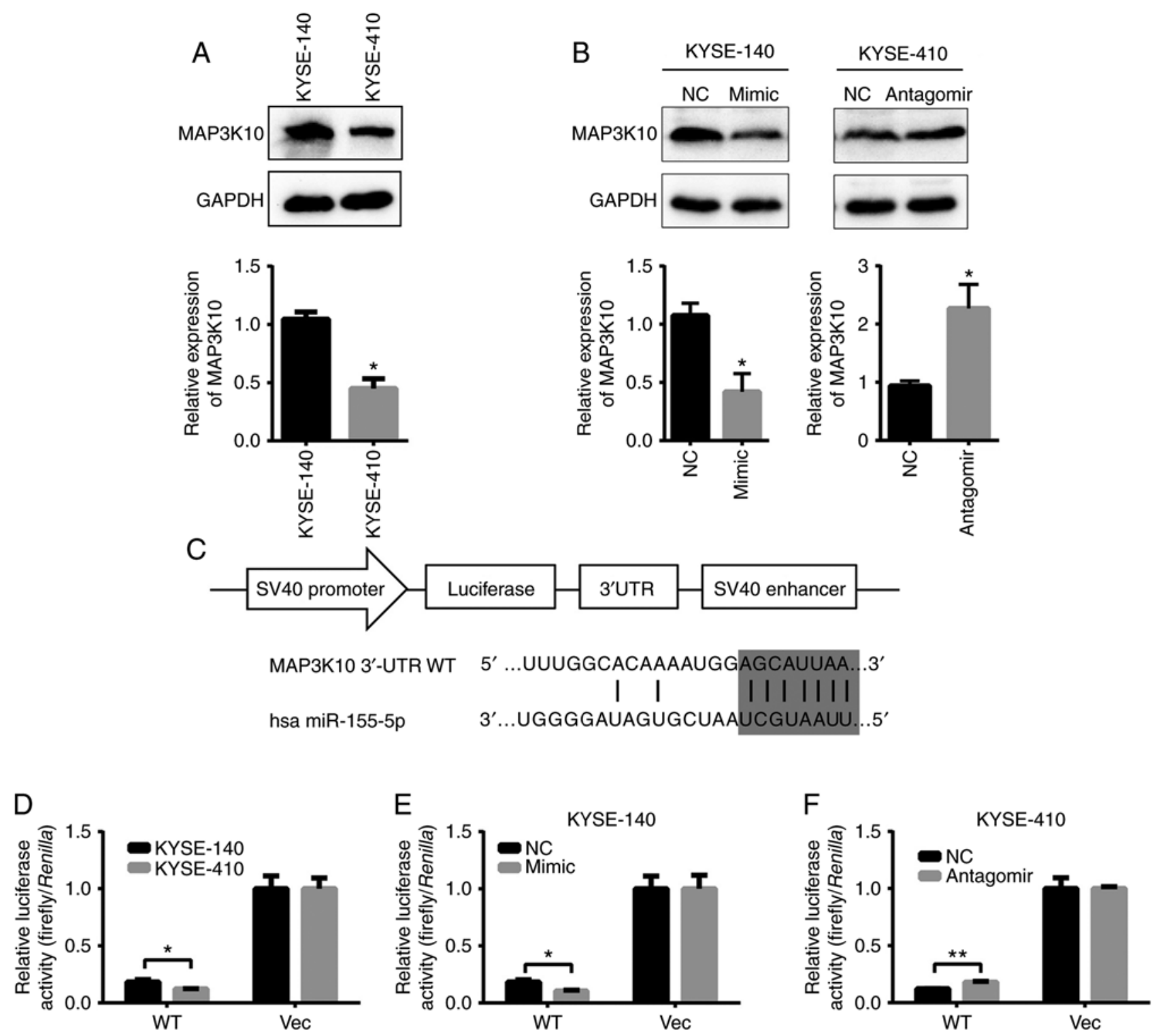

Figure 6. MAK3K10 is the target gene of mir-155-5p. (A) Expression of MAP3K10 is higher in KYSE-140 cells than in KYSE-410 cells according to the results of the western blot analysis. (B) The protein level of MAP3K10 in the miR-155-5p mimic-transfected KYSE-140 cells and miR-155-5p antagomir-transfected KYSE-410 cells vs. the NC are determined by western blot analyses. (C) The schematic map of the pGL3-based luciferase reporter constructs where the UTR region (3'-UTR) of MAP3K10 gene was placed at the downstream flank of the luciferase gene. (D) The relative luciferase activity (fold) of the reporter with WT sequence relative to VEC (with no UTR seq) was determined in the KYSE-140 and KYSE-410 cells. (E and F) The relative luciferase activity was also compared in (E) mimic-transfected KYSE-140 cells and the (F) antagomir-transfected KYSE-410 cells with the NC. The representative results from three independent experiments are presented. ${ }^{*} \mathrm{P}<0.05 ;{ }^{* *} \mathrm{P}<0.001$. WT, wild-type.

(Fig. S2E). However, migration speed and invasion capacity were not influenced by forced reversal of MAP3K10 (Fig. S2A-D), indicating that the miR-155-5p regulated the motility of ESCC cells via other target genes. Additionally, MAP3K10 was revealed to be slightly downregulated in ESCC tumor samples but significantly upregulated in esophageal adenocarcinoma (EAC) compared with normal tissues based on Oncomine database (Fig. S3), which indicated that it may not contribute to tumorigenesis in ESCC as that in EAC, but induced chemoradio-resistance in ESCC.

MAP3K10 is a member of the serine/threonine kinase family, which preferentially activates the C-Jun N-terminal kinase (JNK) signaling pathway (37). The present study examined the JNK pathway activity by Qiagen ${ }^{\mathrm{TM}}$ pathway reporter assay and revealed that it was $\sim 5$-fold higher in KYSE-140 cells than in KYSE-410 cells (Fig. 7G). Furthermore, suppression of MAP3K10 by siRNA or mimic transfection decreased the JNK signaling activity by $\sim 50 \%$ in KYSE-140 cells (Fig. 7H). Conversely, the activity was upregulated by $>1.4$-fold in antagomiR- and MAP3K10-GFP-transfected KYSE-410 cells (Fig. 7I). Therefore, MAP3K10 mediated the promoting effect of miR-155 on resistance against both radiation and drug treatment in ESCC cells, via its effect on the JNK signaling pathway.

\section{Discussion}

The overall prognosis for ESCC is poor, due to diagnosis at advanced stages of disease, high incidences of tumor recurrence and metastasis, and the insensitivity to radiotherapy and chemotherapy. Several clinical trials have demonstrated that 

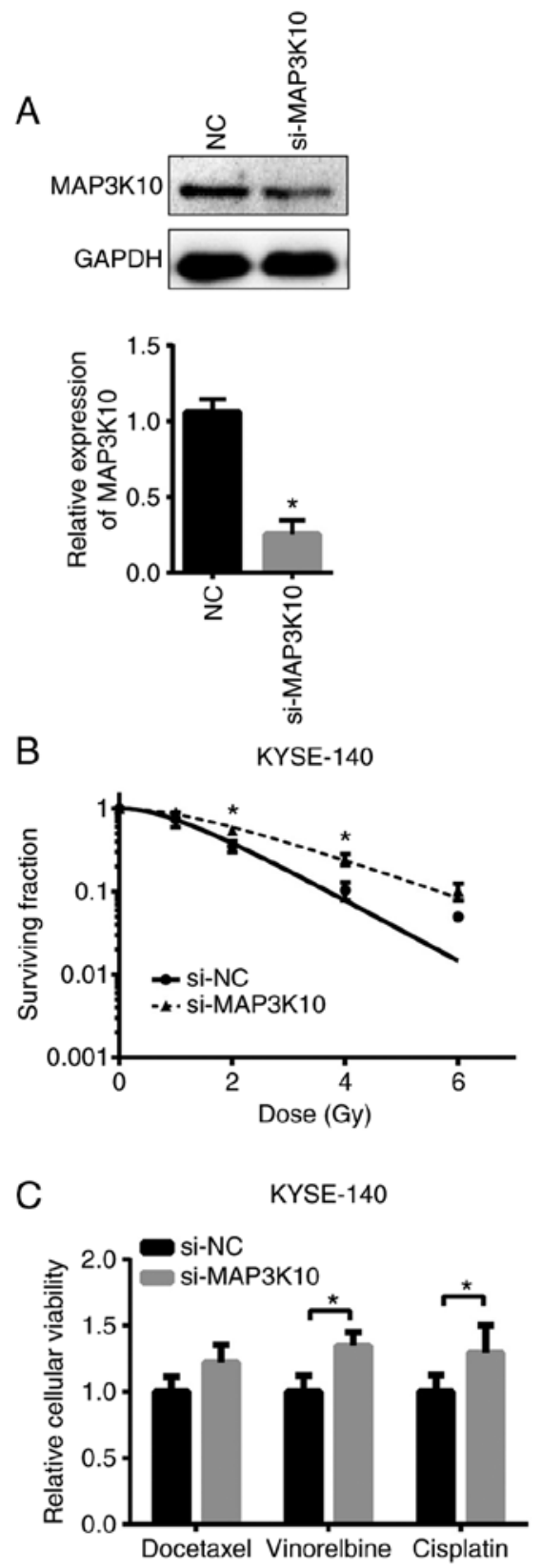
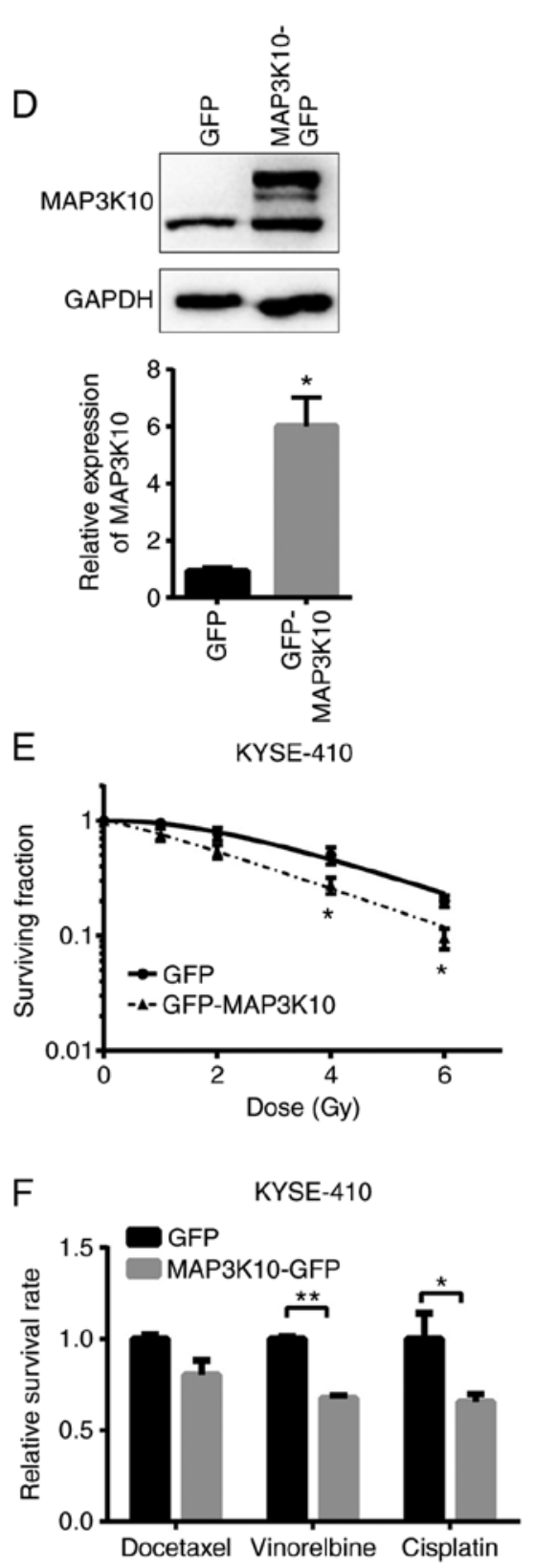

G
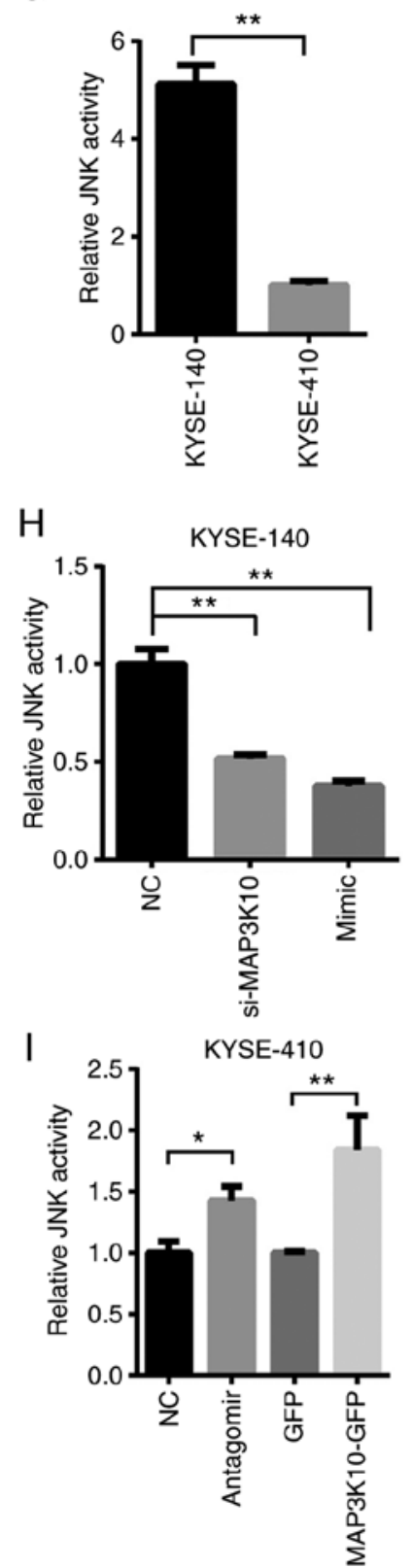

Figure 7. MAP3K10 exerts the promoting effect of miR-155-5p on radio- and chemo-resistance via regulation of JNK pathway activity. (A) Transfection of MAP3K10 siRNA (si-MAP3K10) into KYSE-140 cells downregulated its expression. Suppression of MAP3K10 resulted in (B) significant radiation resistance and (C) multi-drug resistance. (D) The MAP3K10 protein level in the GFP-tagged overexpression construct transfected vs. the GFP-transfected KYSE-410 cells. (E and F) Upregulation of MAP3K10 significantly reduced the resistance against (E) radiation and (F) multi-drug resistance in KYSE-410 cells. (G) The relative activity of the JNK pathway in KYSE-140 vs. KYSE-410 cells. (H and I) Effects of the forced reversal of both miR-155-5p and MAP3K10 expression on the activity of the JNK signaling pathway in (H) KYSE-140 and (I) KYSE-410 cells. ${ }^{*} \mathrm{P}<0.05 ;{ }^{* *} \mathrm{P}<0.001$. JNK, C-Jun N-terminal kinase.

the response to chemoradiation is crucial for the prognosis of patients (5-7); thus, finding molecular markers that can predict the benefits of chemoradiotherapy for patients with ESCC can prevent discomfort and toxicity. The present study demonstrated that miR-155-5p expression under the negative control of DNA methylation conferred ESCC cell resistance against both radiation and chemotherapy drugs in vitro, in agreement with the in vivo data that high expression of miR-155 in patients with ESCC revealed a worse prognosis than those with low expression (38). Consistent with its status as an
oncomiR in other tumors (39-41), it was also revealed that miR-155-5p could enhance proliferation, migration and invasion of ESCC cells. In addition, it has been previously reported that miR-155 promotes cancer progression via inhibition of apoptosis, inducement of EMT and metastasis, and increased risk for recurrence (17-19).

It has been proposed that repair of DNA damage is essential for the maintenance of genomic stability and tumor cell survival following radiation (33). In the present study, it was revealed that miR-155-5p accelerated DNA damage repair, 
and NHEJ was the major repair pathway for DSBs in ESCC that was responsible for the high efficient DNA repair. As anticipated, enhanced DNA damage repair capacity led to resistance to radiation. These results are consistent with the viewpoint that NHEJ acts during any phase of the cell cycle and is the primary mechanism for the repair of DSBs induced by radiation (42); however, this is contrary to a study on breast cancer in which it was revealed that miR-155-5p decreased the efficiency of homologous recombination repair and enhanced sensitivity to radiation by targeting RAD51 directly (23). The present study demonstrated that the expression of RAD51 was not down-/up-regulated in the miR-155-5p mimic/antagomir-transfected cells. This may be due to the different interactions of miRNA-mRNAs in different types of cancer (43). Thus, miR-155-5p binds to other target genes in ESCC and promotes chemoradio-resistance. Given that the level of Ku80 changed only when radiation occurred in the present study, it was supposed that Ku80 is indirectly regulated by miR-155-5p through other mediators after radiation. Further investigations are required in order to confirm the association between Ku80 and miR-155-5p.

Radioresistance may occur simultaneously with chemoresistance in patients with cancer (44). In fact, in the present study, miR-155-5p also enhanced chemoresistance, and this impact was drug type-specific. The intrinsic response of cancer cells to chemotherapy drugs may be different due to the different drug properties. First, the anticancer effect of chemotherapeutic drugs was achieved through various mechanisms. For example, cisplatin induces covalent crosslinks between DNA bases, interferes with DNA repair mechanisms and causes DNA damage and subsequently apoptosis in cancer cells (45). Docetaxel not only inhibits depolymerization of microtubules, but also induces apoptosis by binding to $\mathrm{Bcl}-2$ or $\mathrm{Bcl}-\mathrm{xL}$ and thus arresting the function of each (46). Second, unlike the target therapeutics, the pathways challenged by the conventional chemotherapeutics remain unclear. It has previously been reported that different drugs affect specific signaling pathways in tumor cells, and thus the response of these pathways to drugs was revealed to be both cell type- and drug type-specific (47). Furthermore, it was revealed that certain drugs such as 5-fluorouracil had no effect on miR-155-5p mimic, but had an effect on antagomir. It is proposed that the signaling pathways involved in 5-fluorouracil transport and metabolism may be mutant or defective in KYSE-140 cells. In this case, forced reversion of miR-155-5p may not help to change the cell survival rate under 5-fluorouracil treatment. It is a question worth further investigation. Therefore, miR-155-5p induced resistance to docetaxel, cisplatin and vinorelbine in ESCC cells, potentially by involving certain signaling pathways.

A miRNA executes its biological function via repression in a sequence-specific manner of up to $\sim 2,000$ protein-coding genes at both stability and translation levels of mRNAs. The present study defined the role of MAP3K10, the direct target of miR-155-5p and relayed the impact of miR-155-5p on the ESCC radio- and chemo-resistance through regulation of JNK pathway activity. A previous study revealed that knockdown of MAP3K10 sensitized pancreatic cancer cells to gemcitabine (48). However, the opposite was observed in the present study. siRNA-mediated suppression of MAP3K10 enhanced rather than suppressed the multi-chemoresistance and radio-resistance of ESCC cells. The functional disparity in cancer biology of MAP3K10 is likely attributed to the system difference of studies concerning the type of cancer with different expression patterns of MAP3K10. Compared with tumor-adjacent normal tissue, increased MAP3K10 expression was observed in pancreatic ductal adenocarcinoma (PDAC) tissues and cells (48). However, it was observed to be slightly downregulated in ESCC tumor samples following a hierarchical clustering analysis of gene expression through the Oncomine database and gene microarray data analysis (49). In another study, genome-wide gene expression profiling revealed that MAP3K10 was significantly upregulated in esophageal adenocarcinoma (EAC) compared with normal tissues when assessing with DNA microarray technology (50). As mutations in MAP3K10 are rare in esophageal cancer, according to TCGA analysis, it is proposed that the epigenetic modification of MAP3K10 at the post-transcriptional level may be a crucial factor leading to its misregulation in esophageal cancer. Therefore, these results indicated that MAP3K 10 may not participate in tumorigenesis in ESCC such as in PDAC and EAC, but confer sensitivity to radiation and drugs in ESCC.

In summary, the present study revealed that miR-155-5p, whose expression under the control of DNA methylation confers resistance to radiation and chemotheraputic drugs, enhanced proliferation, migration and invasion, and promoted DNA damage repair by repairing the DSBs more efficiently. MAP3K10 significantly contributed to the positive control of ESCC chemoradio-resistance and proliferation via the JNK pathway. The present study provides a new set of diagnostic targets for the guided personalized chemotherapy of ESCC.

\section{Acknowledgements}

We thank Dr Zhang for his help in revising the final manuscript. Special thanks to Professor Zhan from the National Laboratory of Molecular Oncology, for kindly providing the ESCC cell lines.

\section{Funding}

The present study was supported by the National Natural Science Foundation of China (81602230, 81502191 and 81402327), and the Anhui Provincial Natural Science Foundation (1508085SMH233, 1508085QH178 and $1508085 \mathrm{QH} 183)$. The funders had no role in the design of the study; in the collection, analyses, or interpretation of data, in the writing of the manuscript, and in the decision to publish the results.

\section{Availability of data and materials}

The datasets used and/or analyzed during the current study are available from the corresponding author on reasonable request.

\section{Authors' contributions}

LL and LQ conceived and designed the study. WL, HZ, XL, RX, HD and QY acquired the data. LL and QY analyzed and 
interpreted the data (e.g., statistical analysis, biostatistics, computational analysis). WL, LL and LQ wrote, reviewed, and/or revised the study. All authors read and approved the final manuscript and agree to be accountable for all aspects of the research in ensuring that the accuracy or integrity of any part of the work are appropriately investigated and resolved.

\section{Ethics approval and consent to participate}

Not applicable.

\section{Patient consent for publication}

Not applicable.

\section{Competing interests}

The authors declare that they have no competing interests.

\section{References}

1. Bray F, Ferlay J, Soerjomataram I, Siegel RL, Torre LA and Jemal A: Global cancer statistics 2018: GLOBOCAN estimates of incidence and mortality worldwide for 36 cancers in 185 countries. CA Cancer J Clin 68: 394-424, 2018.

2. Smyth EC, Lagergren J, Fitzgerald RC, Lordick F, Shah MA, Lagergren $P$ and Cunningham D: Oesophageal cancer. Nat Rev Dis Primers 3: 17048, 2017.

3. Napier KJ, Scheerer M and Misra S: Esophageal cancer: A Review of epidemiology, pathogenesis, staging workup and treatment modalities. World J Gastroint Oncol 6: 112-120, 2014.

4. Pennathur A, Gibson MK, Jobe BA and Luketich JD: Oesophageal carcinoma. Lancet 381: 400-412, 2013.

5. Morgan MA, Lewis WG, Crosby TD, Escofet X, Roberts SA, Brewster AE, Harvard TJ and Clark GW: Prospective cohort comparison of neoadjuvant chemoradiotherapy versus chemotherapy in patients with oesophageal cancer. Br J Surg 94: $1509-1514,2007$.

6. Tepper J, Krasna MJ, Niedzwiecki D, Hollis D, Reed CE, Goldberg R, Kiel K, Willett C, Sugarbaker D and Mayer R: Phase III trial of trimodality therapy with cisplatin, fluorouracil radiotherapy, and surgery compared with surgery alone for esophageal cancer: CALGB 9781. J Clin Oncol 26: 1086-1092, 2008.

7. van Hagen P, Hulshof MC, van Lanschot JJ, Steyerberg EW, van Berge Henegouwen MI, Wijnhoven BP, Richel DJ, Nieuwenhuijzen GA, Hospers GA, Bonenkamp JJ, et al: Preoperative chemoradiotherapy for esophageal or junctional cancer. N Engl J Med 366: 2074-2084, 2012.

8. Kloosterman WP and Plasterk RH: The diverse functions of microRNAs in animal development and disease. Developmental Cell 11: 441-450, 2006

9. Tam W: Identification and characterization of human BIC, a gene on chromosome 21 that encodes a noncoding RNA. Gene 274 157-167, 2001.

10. Eis PS, Tam W, Sun L, Chadburn A, Li Z, Gomez MF, Lund E and Dahlberg JE: Accumulation of miR-155 and BIC RNA in human B cell lymphomas. Proc Natl Acad Sci USA 102: 3627-3632, 2005.

11. Zang YS, Zhong YF, Fang Z, Li B and An J: miR-155 inhibits the sensitivity of lung cancer cells to cisplatin via negative regulation of Apaf-1 expression. Cancer Gene Ther 19: 773-778, 2012.

12. Johansson J, Berg T, Kurzejamska E, Pang MF, Tabor V, Jansson M, Roswall P, Pietras K, Sund M, Religa P and Fuxe J: miR-155-mediated loss of C/EBPbeta shifts the TGF- $\beta$ response from growth inhibition to epithelial-mesenchymal transition, invasion and metastasis in breast cancer. Oncogene 32: 5614-5624, 2013

13. Gironella M, Seux M, Xie MJ, Cano C, Tomasini R, Gommeaux J, Garcia S, Nowak J, Yeung ML, Jeang KT, et al: Tumor protein 53 -induced nuclear protein 1 expression is repressed by miR-155, and its restoration inhibits pancreatic tumor development. Proc Natl Acad Sci USA 104: 16170-16175, 2007.
14. Cao H, Huang S, Liu A and Chen Z: Up-regulated expression of miR-155 in human colonic cancer. J Cancer Res Ther 14: 604-607, 2018.

15. Liu R, Liao J, Yang M, Shi Y, Peng Y, Wang Y, Pan E, Guo W, $\mathrm{Pu}$ Y and Yin L: Circulating miR-155 expression in plasma: A potential biomarker for early diagnosis of esophageal cancer in humans. J Toxicol Environ Health A 75: 1154-1162, 2012.

16. Zhang J, Cheng C, Yuan X, He JT, Pan QH and Sun FY: microRNA-155 acts as an oncogene by targeting the tumor protein 53-induced nuclear protein 1 in esophageal squamous cell carcinoma. Int J Clin Exp Pathol 7: 602-610, 2014.

17. Zhang W, Ji W and Zhao X: miR-155 promotes anaplastic thyroid cancer progression by directly targeting SOCS1. BMC Cancer 19: 1093, 2019.

18. Li DP, Fan J, Wu YJ, Xie YF, Zha JM and Zhou XM: miR-155 up-regulated by TGF- $\beta$ promotes epithelial-mesenchymal transition, invasion and metastasis of human hepatocellular carcinoma cells in vitro. Am J Transl Res 9: 2956-2965, 2017.

19. Zhang J, Ye Y, Chang DW, Lin SH, Huang M, Tannir NM, Matin S, Karam JA, Wood CG, Chen ZN and Wu X: Global and Targeted miRNA expression profiling in clear cell renal cell carcinoma tissues potentially links miR-155-5p and miR-210-3p to both tumorigenesis and recurrence. Am J Pathol 188: 2487-2496, 2018.

20. Shao C, Yang F, Qin Z, Jing X, Shu Y and Shen H: The value of miR-155 as a biomarker for the diagnosis and prognosis of lung cancer: A systematic review with meta-analysis. BMC Cancer 19: 1103, 2019.

21. Gao S, Zhao ZY, Zhang ZY, Zhang Y and Wu R: Prognostic value of MicroRNAs in esophageal carcinoma: A meta-analysis. Clin Transl Gastroenterol 9: 203, 2018.

22. Pouliot LM, Chen YC, Bai J, Guha R, Martin SE, Gottesman MM and Hall MD: Cisplatin sensitivity mediated by WEE1 and CHK1 is mediated by miR-155 and the miR-15 family. Cancer Res 72: 5945-5955, 2012.

23. Gasparini P, Lovat F, Fassan M, Casadei L, Cascione L, Jacob NK, Carasi S, Palmieri D, Costinean S, Shapiro CL, et al: Protective role of miR-155 in breast cancer through RAD51 targeting impairs homologous recombination after irradiation. Proc Natl Acad Sci USA 111: 4536-4541, 2014

24. Zhao K, X, Chen X, Zhu Q, Yin F, Ruan Q, Xia J and Niu Z: Inhibition of miR-140-3p or miR-155-5p by antagomir treatment sensitize chordoma cells to chemotherapy drug treatment by increasing PTEN expression. Eur J Pharmacol 854: 298-306, 2019.

25. Babar IA, Czochor J, Steinmetz A, Weidhaas JB, Glazer PM and Slack FJ: Inhibition of hypoxia-induced miR-155 radiosensitizes hypoxic lung cancer cells. Cancer Biol Ther 12: 908-914, 2011.

26. Meng F, Qian L, Lv L, Ding B, Zhou G, Cheng X, Niu S and Liang Y: miR-193a-3p regulation of chemoradiation resistance in oesophageal cancer cells via the PSEN1 gene. Gene 579: 139-145, 2016.

27. Lv L, Deng H, Li Y, Zhang C, Liu X, Liu Q, Zhang D, Wang L, $\mathrm{Pu} \mathrm{Y}$ and Zhang $\mathrm{H}$, et al: The DNA methylation-regulated miR-193a-3p dictates the multi-chemoresistance of bladder cancer via repression of SRSF2/PLAU/HIC2 expression. Cell Death Dis 5: e1402, 2014.

28. Tang F, Hajkova P, Barton SC, O'Carroll D, Lee C, Lao K and Surani MA: 220-plex microRNA expression profile of a single cell. Nat Protoc 1: 1154-1159, 2006.

29. Livak KJ and Schmittgen TD: Analysis of relative gene expression data using real-time quantitative PCR and the 2(-Delta Delta C(T)) method. Methods 25: 402-408, 2001.

30. Zhang JX, Chen ZH, Xu Y, Chen JW, Weng HW, Yun M, Zheng ZS, Chen C, Wu BL, Li EM, et al: Downregulation of MicroRNA-644a promotes esophageal squamous cell carcinoma aggressiveness and stem cell-like phenotype via dysregulation of PITX2. Clin Cancer Res 23: 298-310, 2017.

31. Ma K, He Y, Zhang H, Fei Q, Niu D, Wang D, Ding X, Xu H, Chen $X$ and Zhu J: DNA methylation-regulated miR-193a-3p dictates resistance of hepatocellular carcinoma to 5-fluorouracil via repression of SRSF2 expression. J Biol Chem 287: 5639-5649, 2012.

32. Lord CJ and Ashworth A: The DNA damage response and cancer therapy. Nature 481: 287-294, 2012.

33. Powell SN and Bindra RS: Targeting the DNA damage response for cancer therapy. DNA Repair (Amst) 8: 1153-1165, 2009.

34. Ivashkevich A, Redon CE, Nakamura AJ, Martin RF and Martin OA: Use of the gamma-H2AX assay to monitor DNA damage and repair in translational cancer research. Cancer Lett 327: 123-133, 2012. 
35. Bouwman P and Jonkers J: The effects of deregulated DNA damage signalling on cancer chemotherapy response and resistance. Nat Rev Cancer 12: 587-598, 2012.

36. Lujambio A, Ropero S, Ballestar E, Fraga MF, Cerrato C, Setién F, Casado S, Suarez-Gauthier A, Sanchez-Cespedes M, Git A, et al: Genetic unmasking of an epigenetically silenced microRNA in human cancer cells. Cancer Res 67: 1424-1429, 2007.

37. Nagata K, Puls A, Futter C, Aspenstrom P, Schaefer E, Nakata T, Hirokawa N and Hall A: The MAP kinase kinase kinase MLK2 co-localizes with activated JNK along microtubules and associates with kinesin superfamily motor KIF3. EMBO J 17: 149-158, 1998.

38. Nagy A, Lanczky A, Menyhart O and Gyorffy B: Author Correction: Validation of miRNA prognostic power in hepatocellular carcinoma using expression data of independent datasets. Sci Rep 8: 11515, 2018.

39. Li N, Cui T, Guo W, Wang D and Mao L: miR-155-5p accelerates the metastasis of cervical cancer cell via targeting TP53INP1. Onco Targets Ther 12: 3181-3196, 2019.

40. Qu Y, Zhang H, Sun W, Han Y, Li S, Qu Y, Ying G and Ba Y. MicroRNA-155 promotes gastric cancer growth and invasion by negatively regulating transforming growth factor- $\beta$ receptor 2 . Cancer Sci 109: 618-628, 2018.

41. Ji H, Tian D, Zhang B, Zhang Y, Yan D and Wu S: Overexpression of miR-155 in clear-cell renal cell carcinoma and its oncogenic effect through targeting FOXO3a. Exp Ther Med 13: 2286-2292, 2017.

42. Wang C and Lees-Miller SP: Detection and repair of ionizing radiation-induced DNA double strand breaks: New developments in nonhomologous end joining. Int J Radiat Oncol Biol Phys 86: 440-449, 2013

43. Chiu YC, Tsai MH, Chou WC, Liu YC, Kuo YY, Hou HA, Lu TP, Lai LC, Chen Y, Tien HF and Chuang EY: Prognostic significance of NPM1 mutation-modulated microRNA-mRNA regulation in acute myeloid leukemia. Leukemia 30: 274-284, 2016.
44. Kang Y, Park MA, Heo SW, Park SY, Kang KW, Park PH and Kim JA: The radio-sensitizing effect of xanthohumol is mediated by STAT3 and EGFR suppression in doxorubicin-resistant MCF-7 human breast cancer cells. Biochim Biophys Acta 1830: 2638-2648, 2013.

45. Dasari S and Tchounwou PB: Cisplatin in cancer therapy: Molecular mechanisms of action. Eur J Pharmacol 740: 364-378, 2014.

46. Pienta KJ: Preclinical mechanisms of action of docetaxel and docetaxel combinations in prostate cancer. Semin Oncol 28: 3-7, 2001.

47. Liu Q, Zhang C, Ding X, Deng H, Zhang D, Cui W, Xu H, Wang Y, $\mathrm{Xu}$ W, Lv L, et al: Preclinical optimization of a broad-spectrum anti-bladder cancer tri-drug regimen via the Feedback System Control (FSC) platform. Sci Rep 5: 11464, 2015.

48. An Y, Cai B, Chen J, Lv N, Yao J, Xue X, Tu M, Tang D, Wei J, Jiang K, et al: MAP3K10 promotes the proliferation and decreases the sensitivity of pancreatic cancer cells to gemcitabine by upregulating Gli-1 and Gli-2. Cancer Lett 329: 228-235, 2013.

49. Su H, Hu N, Yang HH, Wang C, Takikita M, Wang QH, Giffen C, Clifford R, Hewitt SM, Shou JZ, et al: Global gene expression profiling and validation in esophageal squamous cell carcinoma and its association with clinical phenotypes. Clin Cancer Res 17: 2955-2966, 2011

50. Kim SM, Park YY, Park ES, Cho JY, Izzo JG, Zhang D, Kim SB, Lee JH, Bhutani MS, Swisher SG, et al: Prognostic biomarkers for esophageal adenocarcinoma identified by analysis of tumor transcriptome. PLoS One 5: e15074, 2010. 